\title{
Feed efficiency, nutrient sensing and feeding stimulation in aquaculture: a review
}

\author{
Csaba Hancz * \\ Kaposvár University, Faculty of Agricultural and Environmental Sciences, H-7400 Kaposvár,
} Guba S. 40.

\begin{abstract}
Ameliorating of feed efficiency always was and will remain the key element of aquaculture in which minimalizing losses during feed intake play an important role. Decreasing feed losses important not only from the economic point of view but also from an environmental standpoint. Feeding stimulants are often used additives in complete aquaculture feeds. Better knowledge of the food-sensing of cultured species is essential in the development of adequate feeding stimulants. The present paper aims to overview the nutrient-sensing of aquatic animals and the use of the wide variety of feeding attractants and stimulants.
\end{abstract}

Keywords: feeding, feed efficiency, food sensing, attractants, stimulants

\section{INTRODUCTION}

Global aquaculture production showed impressive growth in the last decades. According to FAO statistics it reached 110.2 million tons in 2016 that included 80.0 million tons of food fish and 30.1 million tons of aquatic plants. Based on the assumption of higher demand and technological improvements, total world fish production (capture plus aquaculture, excluding aquatic plants) is expected to continue to expand over the course of the projection period to reach 201 million tons in 2030. The major growth in production is expected to originate from aquaculture, which is projected to reach 109 million tons in 2030. Capture fisheries production (inland and marine) is stagnating around 90 million tons since 2011 while farm-raised fish and shrimp will account for nearly two-thirds of seafood consumption worldwide by 2030 (FAO, 2018). Since sustainability continues to be a concern, development in aquaculture must adopt a holistic philosophy such it appears in the ecosystem approach to aquaculture (EAA) that may play an important role in the future "blue growth" (Brugère et al., 2018).

Innumerable studies aimed to give information about the feed utilization were carried on for fish and other cultured species in the last decades because of the simple fact that feed and feeding comprise determining part of production costs in aquaculture. There are numerous ways of achieving a better feed efficiency, a key element of the impressive growth of aquaculture achieved in

\footnotetext{
*CORRESPONDING AUTHOR 
the last decades. Extensive development of compound feeds based on more sophisticated knowledge of nutrient requirements of more and more aquaculture species (Webster and Lim, 2002) certainly played an important role in this process as well as detailed and accurate theoretical models of fish metabolism (Braaten, 1979; Smith, 1980; Kaushik and de Olivia-Teles, 1985; Tytler and Calow, 1985; Kaushik, 1986; Johnston and Dunn, 1987; Dietz et al., 2013; Jobling, 1998; Clarke and Johnston, 1999; Bureau et al., 2002; Stadtlander et al., 2013). The great majority of the literature on feed efficiency discusses traditionally the simplest indicators, that is feed conversion ratio (FCR) or its inverse, feed efficiency ratio (FER) calculated as the simple ratio of input and output or vice versa, where the feed is the input and the output is the weight gain. Better digestibility of nutrients means lower FCR so a determination of apparent digestibility coefficient (ADC) makes part of nowadays' feeding studies (Grisdale-Helland et al., 2013; Heinitz et al., 2015). Although the determination of ADC doesn't have a generally used, standardized method till now, it has many advantages over measuring correctly the metabolizable energy of nutrients of fish foods or industrial feeds (Lovell, 1989). Based on these theoretical grounds, continuously tested in the practice, very intense development of the feed industry has emerged. Up-to-date complete feeds have to satisfy all physiological requirements of the targeted age-group of the cultured species and also the special demands of the technology version applied. To meet these goal feed additives are used in feed formulation from the beginnings of the modern aquaculture industry. According to Tacon (1987) feed additives are substances which are added in trace amounts to a diet or feed ingredient with the following purposes: 1) to preserve its nutritional characteristics prior to feeding (antioxidants and mold inhibitors), 2) to facilitate ingredient dispersion or feed pelleting (emulsifiers, stabilizers, and binders), 3) to foster growth (growth promoters, including antibiotics and hormones), 4) to facilitate feed ingestion and consumer acceptance of the product (feeding stimulants and food colorants), or 5) to supply essential nutrients in purified form (vitamins, minerals, amino acids, cholesterol, and phospholipids). Although some criticism may be justified about the logic of the above classification, it summarizes quite well the feed additives and their purposes. The choice of feed additives has changed a lot in the last decades as accompanying the goal of long-term profitability, environmental, economic and social sustainability started to gain more and more emphasis. Natural feed additives proved to be efficient, reducing the need for medicated treatments, decrease metabolic waste production and improve fillet quality (Gonçalves and Santos, 2017). Pre- and probiotics became routinely used as well as special feed additives like exogenous enzymes 
(Hardy, 2000; Cerezuela et al., 2011; Kazerani and Shahsavani, 2011; Ganguly et al., 2013; Carnevali et al., 2017) or phytic acid (Liu et al., 2017). Application of phytochemicals that can affect fish health, growth and feed utilization is also spreading as extensive use of antibiotics has encouraged the evolution of resistant bacteria (Chakraborty and Hancz, 2011; Chakraborty et al., 2013). Encarnação (2016) gives an up-to-date summary of feed additives and introduces a new category of feeds called functional feeds for compound aquaculture feeds made with additives for ameliorating the animals' performance and improving intestinal health, stress, and disease resistance.

The goal of the present paper was to overview the nutrient-sensing of aquatic animals and the use of feeding attractants and stimulants, a somewhat neglected group of feed additives.

\section{FEED EFFICIENCY, FOOD INTAKE, AND NUTRIENT SENSING}

\section{Feed efficiency}

For optimizing feed efficiency qualitative and quantitative nutrient requirements of the producing organisms have to be met parallelly. However developing the most economically producible feed that satisfies the nutritional requirements of a given age-group of the cultured species continues to be among the primary goals of the aquaculture industry, other aspects of decreasing feeding costs - related to certain details of feeding technology - also are important.

Minimizing feeding loss, which from a broader point of view contains the indigestible part as well as all metabolic losses, is crucial but we must not forget the simple fact that one, not a negligible fraction of the offered feed is uneaten. Uneaten part of the feed is varying a lot but can be estimated at about $10 \%$ on average (Craig, 2009). Experimental determination of the not ingested feed can be tried with the help of some indicator as it was done by Park et al. (2019) using the added $17 \mathrm{~B}$-estradiol in feed for American eel in recirculating aquaculture system (RAS) where uneaten part of feed ranged between 7-13\%. The feed that is not consumed within a reasonable time represents an economic loss and also deteriorate water quality, so feed ration, feeding method, and water stability of the feed have to be considered. Commercial feed pellets have to remain intact in water until being consumed which is especially important for slow feeding aquaculture species such as shrimp (Lovell, 1991). Use of binders as feed additives to ensure water stability is a basic practice for a long time (Tacon, 1987) but does not solve all problems of feed loss. Find appropriate feeding frequency is the most efficient way in decreasing not only 
this direct loss but also in lowering FCR so published feeding rate tables are available for most commonly cultured species (Craig, 2009). Nowadays a great variety of automatic feeders are obtainable for programmed feed delivery in cages, raceways, ponds, and RAS operations, to ensure optimal feeding. Information about the actual feed loss and so optimizing the feeding regime can greatly be facilitated by using monitoring systems in the future, like the one experimented by Parra et al. (2018) who describe a sophisticated sensory system for adjusting the feed supply. Adequate feeding schedule, aiming to minimize feed losses is the base of every technological version applied in aquaculture, however, developing it needs many-sided problem-solving. Problems start with the precise determination of feed intake. Houlihan et al. (2001) edited a whole book of 415 pages discussing in 14 chapters the different aspects of food intake in fish from feed composition to management of feeding. Knowledge of factors influencing the ingestion of feed certainly can lead to improved growth performance and feed utilization by decreasing the amount of waste per unit of fish produced. Difficulties related to determining the exact amount of consumed feed is treated, among many others, by Lovell (1991), Jobling (1998) and Sayer (1998). The palatability of feed is remaining a key question in aquaculture which is discussed among others by Glencross et al. (2007) who point out that fish must be given the opportunity to refuse feed, in experiments aiming to determine ADC. This aspect is especially important in a much broader aspect since the use of alternatives of fish meal (FM) and fish oil (FO), having unfavorable organoleptic and/or antinutritive properties, became a general practice. Although the number of alternative protein sources of animal origin is also increasing (Pucher et al., 2006; Wei et al., 2015; NOAA/USDA, 2011; Magalhães et al., 2017) the plant origin group predominated by soybean products remain pivotal. Alternatives of soybean are also heavily investigated nowadays (Hien et al., 2016; Teuling et al., 2017) and this trend certainly will continue in the future.

\section{Chemoreception and food sensing}

Neuro-hormonal control of chemoreception of teleost fish is well studied (Vahl, 1979; Hara, 1992; Hara, 1994; Michel, 2006; Volkoff, 2016; Conde-Sieira and Soengas, 2017; Delgado et al., 2017; Morais, 2017; Rønnestadt et al., 2017) which cannot be declared about lower taxa involved in aquaculture (Lindstedt, 1971). In farming two concepts of chemosensory aspects of food and their potential effects on feeding behavior have to be taken into account: chemical attraction and feeding stimulation. Both affect aquaculture productivity but in different ways. 
The basic steps of feeding behavior are illustrated in Figure 1.

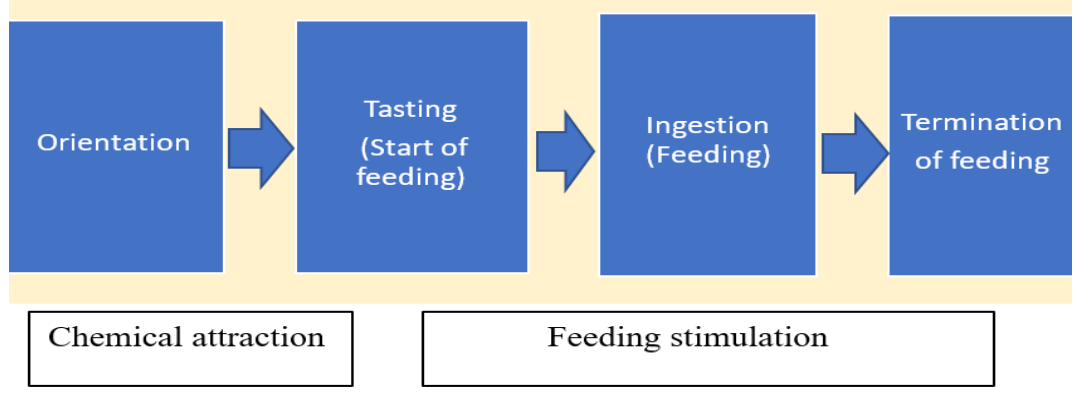

Figure 1. Basic steps of feeding behavior (Modified after Lindstedt, 1971)

Attractants in feed lead to faster feeding and a reduction in feed wastage, improving water quality and eventually reducing feeding costs. Feeding stimulants affect satiation and therefore modulate the total amount of ingested food. Multiple sensorial stimuli are involved in feeding but evidence suggests that tasting plays a more important role than olfaction in the feeding behavior of fish (Morais, 2017). Fish use olfaction and gustation to distinguish between similar types of food and evolved multiple sets of feeding behaviors (Jones, 1992; Valentinčič, 2005). Olfaction and gustation detect overlapping sets of somewhat common metabolic products from which amino acids are the most important. Crustaceans use antennular chemoreception to identify food (Derby 2000; Derby et al., 2001) locating it from a distance in which amino acids and nucleotides are two major sets of molecules that they use. While olfaction is organized to adaptively integrate information associated with a wide range of chemical stimuli for various functions (reproduction, migration, schooling) gustation is specialized for sensitivity and localization of food source (Derby and Sorensen, 2008). There is a paucity in studies like made by Kasumyan and Tinkova (2013) who examined the taste attractiveness of different hydrobionts for three different fish species or by Olsén and Lundh, (2016) who tested the reception of agar pellets prepared with extracts of mussel meat, koi carp feed and a commercial cyprinid bait on crucian carp. However, some excellent behavioral studies were made for intensively produced species testing various, broadly applied feeding stimulants as betaine and taurine (Carlberg et al., 2015; Lim et al.,2016 (a, b). Miyasaki and Harada (2002) carried out a sophisticated estimation of feeding stimulation activity of sugars and nucleic acid-related compounds on four fish and one mollusk species. Alves 
et al. (2020) investigated the attractiveness and palatability of liquid protein hydrolysates for Nile tilapia. Five experimental diets were formulated containing 5\% inclusion of fishmeal (FPE; positive control), 5\% inclusion of liquid protein hydrolysate of porcine mucosa (PHM), 5\% inclusion of liquid protein hydrolysate of poultry (PHF), 5\% inclusion of liquid fish oil (OPE) and a diet without fishmeal (negative control). The same amount of pellets was offered and the following feeding behaviors were evaluated with the aid of three-minute footages per feeding. All diets presented negative palatability indexes in comparison to FPE.

The attraction of fish has major importance also in angling, a worldwide popular hobby sustaining an enormous and very lucrative industry offering, among others, a great variety of baits and bait flavorings. For example, a firm (Cathedralbaits.com) offers more than sixty varieties of flavorings from lemon to tuna for common carp baits that are all of plant or animal origin. This seems to be an exaggerated number, notwithstanding the common carp is a highly adaptive omnivorous fish and might be attracted by many feeding stimuli. However, as it will be seen later, the number of scientifically tested feed aroma materials of natural origin is significantly less.

\section{FEEDING STIMULANTS}

Knowledge of the feeding behavior of the fish or shrimp is essential in maximizing the ingestion of the offered feed. The diet presented must have a suitable appearance in size, shape, color, texture, density (buoyancy) and attractiveness (smell or taste) for eliciting an optimal feeding response. Of course, the relative importance of these traits depends on whether the given fish or shrimp species is mainly a visual or a chemosensory feeder, as Tacon (1987) summarizes the basic principles about feeding stimulants. Maximal intake of the offered feed is generally of major importance in all kinds of aquaculture practice, however, in special cases, the use of feed attractants and diet palatability are particularly critical. Lower palatability of high plant-based diets already was mentioned but medicated feed formulation is also an area where the use of attractants is essential (Toften and Jobling, 1997) as well as the weaning of fish larvae from a living to a non-living diet. Smoltification depression of salmon is also an example of special cases (Clarke et al., 1994; Toften et al., 2003).

Potential and already routinely applied attractants and stimulants cannot be classified into distinct groups according to olfaction and gustation because these subsequent phases of feeding behavior and their role differs by species. 
Classification of feeding stimulants, differentiating natural and artificial origin, used by Tacon (1987) seemed to be acceptable, although it has to be stressed that in the great majority of studies discussed here materials of both classes were jointly tested. (References in Tacon (1987) will not be discussed here).

\section{Feeding stimulants from natural ingredient sources}

Feed ingredients with specific attractant properties for shrimp and marine fish are squid meal, mussel flesh, shrimp meal and waste, clam flesh, marine polychaete worms, certain terrestrial oligochaete worms, marine fish oils, fish meal, fish solubles, fish protein hydrolysates, and soybean protein hydrolysates (Tacon, 1987). As it was already mentioned the replacement of dietary fish meal with plant protein is a long-lasting trend in aquaculture that certainly will be continued as FM resources are limited. Consequently, lower feed intake and reduced growth caused by reducing the dietary FM level remains a problem to cope with. Some decades ago, it was a professional commonplace that FM contains an unknown growth factor (UGF) which is acting on fish Andrews and Page (1974) and also on poultry Bjørnstad et al. (1974); Opstvedt and Gjefsen (1975). Since that time lots of "unknows" of this factor became "knowns". Takakuwa et al. (2019) found that feeding stimulatory effect of jack mackerel muscle extract on greater amberjack depended mainly on inosine monophosphate (IMP) while inosine, adenosine monophosphate (AMP), adenosine diphosphate (ADP), and adenosine triphosphate (ATP) less affected relative feed intake (RFI). Senzui et al. (2020) studied the mRNA expression response of neuropeptide Y (NPY), an orexigenic hormone to the detection of a fish meal soluble fraction (FMS), including smell and/or taste of FM, through the sensory organs (olfaction and gustation) in yellowtail Seriola quinqueradiata and found that smell and/or taste of FM might regulate brain NPY mRNA expression in the short term. Products made of fish flesh and fish processing by-products with putative attractant effect are frequently used feed additives. Oliveira and Cyrino (2004) tested six levels of fish silage and soluble fish protein together with Fisharon $^{\text {Tm}}$, a feeding stimulant containing $12 \%$ of cod liver oil and $87 \%$ of corn oil on largemouth bass fed on plant protein-based feed. They found no significant effect of these stimulants on the main performance traits, moreover, not any interpretable trend of the attractant dosages was observed. HirtChabbert et al. (2011) found that incorporations of yeast-based and marinebased feedings stimulants into a pelleted diet had a beneficial effect on the overall performance of European glass eels and elvers. Moreover, in glass eels, $60 \mathrm{~g} \mathrm{~kg}^{-1}$ marine-based stimulant promoted the maturation of the digestive 
function during the weaning process but had no effects on growth performance in elvers. The use of feed ingredients made of invertebrates has also a long history and their stimulant effect was evaluated many times. Kader et al. (2010) investigated the effects of fish soluble (FS), krill meal (KM), squid meal (SM) and crystalline amino acids (CAA) mixed to feeds in which 60\% FM protein was substituted by soybean protein. It was concluded that that supplementation of FS, KM, and SM is as effective as CAA to maintain amino acid balance and can act as attractants in high soybean protein concentrate (SPC) based diets for maintaining normal feeding behavior, growth performance, health and welfare of juvenile red sea bream. Attractant effect of krill meal incorporated in different feeds for pacific white shrimp was evaluated by Sanchez et al. (2005) who found that attraction depended on the ratio of krill meal and also on the type of other protein sources in the feeds. Chatzifotis et al. (2009) investigated the effect of dietary additives on growth and feed efficiency of sea bream (Sparus aurata) fry fed a fishmeal-based diet. The additives (protorsan - (Sopropeche $®)$, hydrolyzed fish protein, squid meal, krill meal, and betaine + inosine-5'- monophosphate) were added to the diets at the expense of fishmeal. (Protorsan is a bacterial protein concentrate generated as a byproduct of the production of L-glutamic acid.) Significant differences in final body weight and SGR rate were detected only between the protorsan and control groups and the squid additive group, in favor of the squid meal, while no significant differences were observed in FCR. Kim and Cho (2019) tested the effects of $5 \%$ of replacement in the control diet (Con) 55\% anchovy meal content by jack mackerel, sardine, Pollack, squid, and shrimp meals referred to as the JM, SM, PM, SQM and SHM diets, respectively on the growth, feed utilization, condition factor (CF) and whole-body composition of rockfish. They found that the greatest weight gain, amount of feed supply and CF of rockfish were obtained in the JM diet, followed by the SM, PM, SQM, SHM and Con diets, in order, while feed efficiency, protein efficiency ratio and protein retention was not affected by the experimental diets, as well as proximate composition of the whole body of fish, except for ash content. Toften et al. (2003) found that squid extract is a feeding stimulant for salmonids, and added to feed at $5 \mathrm{~g} \mathrm{~kg}$ 1 improves the performance of salmon in the parr-smolt transformation period. Squid extract was also tested by Xue et al. (2004) on gibel carp and was expected to enhance the palatability and feeding rate of diets with or without meat and bone meal but its effect was not found significant. Sea clam (ocean quahog Arctica islandica) processing by-products and betaine were tested as feeding stimulants on sunshine bass fed on fishmeal and soy-based diets. It 
was found that the addition of betaine did not improve diet acceptance or intake. However, the inclusion of sea clam by-products, particularly dried clam fines, improved the intake of the reduced fish meal formulation appear to be effective feeding stimulants in soy-based feeds for juvenile sunshine bass (Barry et al., 2016).

Algae, especially microalgae, inter alia, are commercially viable raw material sources for aquaculture (Slaski and Franklin, 2011) containing valuable nutrients and also bioactive compounds (Holdt and Kraan, 2011). However, their feeding stimulant effects were little studied and only on invertebrate species. Angell et al. (2012) carried out a very thorough study on the feeding preferences and the nutritional value of tropical algae for the abalone Haliotis asinine. According to their findings, preference based on nutrition is not a paradigm for all abalone but the overriding factors influencing the feeding preferences are the physical and chemical defenses of algae, both of which can be diminished through the use of carrageenan bound diets. Moreover, mixed algal diets may only reach an optimal amino acid profile if methionine and by histidine is supplemented in diet formulation. Palatability of diets improved by incorporating feeding stimulants from marine plants was investigated on sea urchin $T$. gratilla by Dworjanyn et al. (2007) who found that total protein or energy in the plants did not account for preference. When three artificial diets were made by incorporating dried Ecklonia radiata, Sargassum linearifolium and Ulva lactuca at $5 \%$ sea urchins ate more than twice as much the artificial diet containing $S$. linearifolium compared to the control diet containing no algae in a choice feeding experiment. In a no-choice feeding experiment, they consumed significantly more of the Ecklonia and the Sargassum diets than the control diet despite each of the diets containing approximately the same protein and energy levels. Eventually, it was concluded that the small amounts of palatable seaweed added to the artificial diets act as feeding stimulants, increasing the acceptability of artificial diets, boosting the protein and energy consumption, and significantly increasing the growth of sea urchin.

\section{Purified or synthetic substances as feeding stimulants}

Widespread application of feeding stimulants belonging to this category is based on a vast number of studies that clarified the basics of olfaction and gustation of aquatic (and non-aquatic) animals, aspects soundly discussed by $\mathrm{Mo}$ rais (2017). Although feeding stimulants for herbivorous and carnivorous fish are generally different (Adams and Johnsen, 1986) amino acids (AAs) play a key role in food sensing in both groups. Carr et al. (1996) determined the main 
components in extracts of tissues of 10 species of marine fishes and 20 species of mollusks and crustaceans concluding that two of the major tissue components (Gly and Ala) in these groups are also the two most frequently cited feeding stimulants in 35 teleost species. Mollusks and crustaceans contain high concentrations of five of the most frequently cited stimulants in carnivorous fish (Gly, Ala, Pro, Arg, and betaine). On the other hand, for the herbivorous Tilapia zillii, the major stimulatory AAs (Glu, Asp, Ser, Lys, and Ala) are also particularly abundant in romaine lettuce, a plant which they normally consume (Adams et al., 1988).

Mackie and Mitchell (1983) tested the effects of feeding stimulants on juvenile European eels, Anguilla anguilla and found that mixtures of L-amino acids were stimulatory, while neither the corresponding D-amino acids nor the nonamino acid components were effective. Synergistic effects were also observed both between L-amino acids and between L-amino acids and non-amino acid constituents. Takeda et al. (1984) compared the feeding stimulant effect of a synthetic extract, based on the composition of the marine worm Perinereis brevicirrus with, AAs, nucleotides and other compounds (including taurine, betaine, maltose among others) for juvenile eel, Angilla japonica. Fish showed a marked preference for a diet flavored with the synthetic extract over an unflavored diet and the extract showed that the fraction of the amino acid was most stimulatory, followed by the "other compounds", while the nucleotides fraction including adenosine-5' -monophosphate was inactive or repellent. The active constituent in the amino acid fraction was identified as the fraction glycine, alanine, proline plus histidine whose activity was found to be comparable to that of the complete synthetic extract. A similar methodology was used by Takaoka et al. (1995) who studied feeding stimulants for the tiger puffer Takifugu rubripes testing synthetic extract of clam Tapes japonicus. The amino acid fraction showed remarkably higher feeding stimulant activity than those of nucleotide and other chemical fractions in the extract. Among 18 chemicals in the amino acid fraction, L-serine, L-aspartic acid, glycine, and L-alanine showed slightly higher activity than deionized water, but lower than the amino acid fraction. The mixture of the above four amino acids plus betaine showed a markedly higher feeding stimulant activity than that of the synthetic extract, indicating the synergistic effect. The positive supplement level of the four amino acids plus betaine was found to be that corresponding to $100 \mathrm{~g}$ of clam muscle per $100 \mathrm{~g}$ of casein diet. L-arginine is considered efficacious when used as a flavoring compound in animal nutrition in general $(E F S A, 2018)$. Chen et al. (2016) investigated the effects of dietary arginine levels on growth performance, body composition, serum biochemical indices and resistance ability 
against ammonia-nitrogen stress in juvenile yellow catfish (Pelteobagrus fulvidraco). The results suggested that dietary arginine level at $2.81 \%$ could optimize the anti-ammonia-nitrogen stress ability of juvenile fish, while performance traits were also at $3.23 \%$ arginine level that seemed to depress the growth performance and also their tolerance to the ammonia-nitrogen stress. Supplementation of feeds with AAs is of the primary importance of shrimp and fish feeds that was surveyed by Nunes et al. (2014) from point of view of nutrient requirements. The major conclusion of this review is that the appropriate supplementation of crystalline AAs in feeds for fish and shrimp gives an opportunity to reduce formulation costs, a concern that certainly has precedence over attractiveness. Several different types of substances, besides free AAs, have been recognized as attractive to fish including quaternary amines such as betaine (glycine betaine, trimethylglycine). Application of betaine in aquaculture feeds has a long history and vast literature. Mackie and Mitchell (1982) found that the feeding stimulant requirement of the Dover sole was very specific and only betaine and dimethylthetin proved to be effective. Yeşilayer and Kaymak (2020) investigated the effect of partial replacement of dietary fish meal by soybean meal with betaine attractant supplementation on juvenile rainbow trout and concluded that $1 \%$ betaine supplementation with dietary incorporation of soybean meal at $25 \%$ level positively influenced growth performance, feed utilization and fatty acid profiles of rainbow trout juveniles. The last two studies mentioned above are indicating that that the prosperous era of betaine commencing in the eighties of the last century is continuing until these days. This era also would be named after FinnStim, a trademarked product consisting of $97 \%$ betaine supplemented with $3 \%$ protein hydrolysate. A quick Google Scholar search resulted in more than 150 scores on FinnStim that may give an idea about the vastness of the related literature, which, obviously, cannot be overviewed here. Some studies were aimed to find alternatives for betaine as for example that of Zou et al. (2017) who evaluated the effects of four feeding stimulants on feed intake (FI), growth performance, body composition, serum biochemical parameters, digestive enzyme activities and appetite-related gene expression for juvenile genetically improved farmed tilapia tilapia. Five experimental high plant-based diets (with $0,0.4 \mathrm{~g} \mathrm{~kg}^{-1}$ dimethyl$\beta$-propiothetin (DMPT), $0.6 \mathrm{~g} \mathrm{~kg}^{-1}$ dimethylthetin (DMT), $1.8 \mathrm{~g} \mathrm{~kg}^{-1}$ tryptophan (Trp) and $6 \mathrm{~g} \mathrm{~kg}^{-1}$ betaine (Bet), respectively supplemented) were fed to juvenile GIFT tilapia (Oreochromis $s p$.). The results showed that FI was significantly increased by Trp and DMT. The highest specific growth rate (SGR) and protein efficiency ratio (PER) was observed for fish fed Bet diet, followed by DMT. The 
neuropeptide Y (NPY) mRNA expression in the brain was significantly improved by Trp, and ghrelin mRNA expression in the stomach was significantly increased by DMT. It is concluded that the supplementation of Trp or DMT could act as an effective feeding that might be associated with the relatively higher orexigenic (NPY or ghrelin) gene expression. Supplementation of Bet could improve SGR, PER and reduce feed conversion ratio (FCR). Betaine has been the most effective substance by far, for all the species studied and especially for soleids but at too high a cost, so Reig et al. (2003) evaluated by an ethological methodology the use of a bivalve commercial flavor as an alternative to betaine in sole diets and found that it may be considered a viable alternative to betaine.

Li and Gatlin (2006) gave a sound overview of the roles of nucleotides and metabolites in fish diets. It was stressed that possible involvement in diet palatability, fish feeding behavior and biosynthesis of non-essential amino acids, exogenous nucleotides have shown promise most recently as dietary supplements to enhance immunity and disease resistance of fish produced in aquaculture. However, there are numerous gaps in existing knowledge about exogenous nucleotide application to fish including various aspects of digestion, absorption, metabolism, and influences on various physiological responses especially the expression of immunogenes and modulation of immunoglobulin production. Ringø et al. (2012) in their thorough review don't even mention feeding stimulation in relation to nucleotides. Lim et al. (2016b) evaluated the potential of betaine, taurine, inosine (INO), inosine $5^{\prime}$-monophosphate disodium (IMP·Na2), and guanosine $5^{\prime}$-monophosphate disodium (GMP·Na2) as a feeding stimulant for juvenile marble goby (Oxyeleotris marmoratus) through behavioural assays using agar gel pellets. The pure agar gel pellet was totally rejected by the fish ( $0 \%$ ingestion rate). Of all the chemical substances tested at $0.1 \mathrm{M}$ concentration, the ingestion rates of both INO and IMP·Na2 were the highest (both $100 \%$ ) and were significantly higher than those of the other chemical substances tested. However, INO was identified as the most potent feeding stimulant as it could function perfectly (100\%) even at the lower concentrations tested $(0.01$ and $0.001 \mathrm{M})$. Taurine was not a feeding stimulant, and betaine was neither a feeding stimulant nor feed enhancer for the juvenile O. marmoratus. Xia et al. (2019) studied the influence of different proportions of $5^{\prime}$-inosine monophosphate (IMP) and 5'-guanosine monophosphate (GMP) on growth, feed digestibility and activity of digestive enzymes of turbot Scophthalmus maximus. Weight gain and daily feed intake were significantly higher in fish fed with IMP or GMP, in comparison with fish fed with neither IMP nor 
GMP. The growth of $0.05 \%$ IMP $+0.05 \%$ GMP group was the best, and the intestinal digestive function was improved. The addition of IMP and GMP to fish diets significantly increased the apparent feed digestibility of dry matter and protein, as well as intestinal protease activity. The optimal level of dietary IMP was $1 \mathrm{~g} / \mathrm{kg}$, which is in line with most of the growth performance and feed digestibility.

The most important studies on feeding stimulants are summarized in Table 1.

\section{CONCLUSIONS}

Improving feed efficiency is an evergreen topic in aquaculture research and practice. Balanced complete feeds are available for more and more cultured species satisfying requirements in different developmental phases. Completing feeds also include supplementation with feed additives from which feeding stimulants are must-have.

Better knowledge of food sensing of aquatic animals helps to find the appropriate attractants and stimulants for increasing feed's palatability. Better palatability means more efficient feed intake. Diminishing feed losses is pivotal both from an economic and environmental protection point of view.

Traditional feeding stimulants are the natural ingredients that have an attractive effect and improve the palatability of feeds. The use of fish processing by-products, squid meal, mussel flesh, shrimp meal and waste, clam flesh, etc. is a viable option in developing palatable feeds economically.

Purified or synthetic substances as feeding stimulants were developed on the basis of intense research for identifying the compounds responsible for the attractive effects of the above-mentioned ingredients of natural origin. Use of crystalline AAs is an everyday practice in feed manufacturing to ensure the adequate biological value of the protein content however special mixtures of selected AAs can serve as an effective attractant.

Betain is keeping its important role among feeding stimulants even if the era of FinnStim seems to be ended. Using of nucletoids in aquaculture feeds is a very promising possibility however their stimulant function is questionable. 


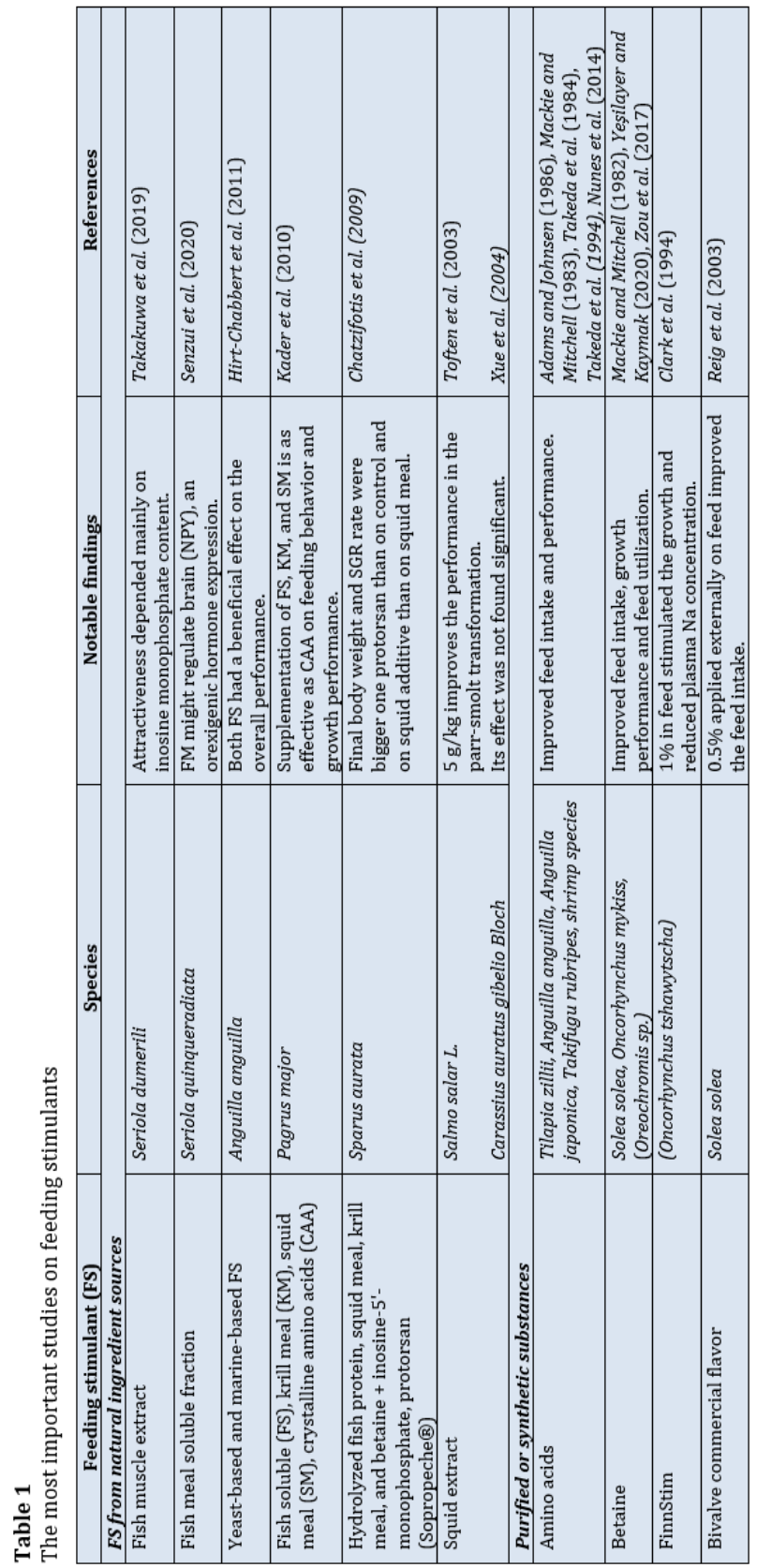




\section{ACKNOWLEDGEMENTS}

\section{The work is supported by the EFOP-3.6.3-VEKOP-16-2017-00008 project. The project is co-financed by the European Union and the EuropeanSocial Fund.}

\section{REFERENCES}

Adams, M. A. and Johnsen, P. B. (1986). A solid matrix bioassay for determining chemical feeding stimulants. The Progressive Fish-Culturist, 48(2), 147-149. DOI: 10.1577/15488640(1986)48<147:asmbfd $>2.0 . c 0 ; 2$

Adams, M. A., Johnsen, P. B. and Zhou, H-Q. (1988). Chemical enhancement of feeding for the herbivorous fish Tilapia zillii. Aquaculture, 72(1-2), 95-107. DOI: 10.1016/0044-8486(88)90150-0

Alves, D. R. S., Oliveira, S. R., Luczinski, T. G., Boscolo, W. R., Bittencourt, F., Signor, A., and Detsch, D. T. (2020). Attractability and palatability of liquid protein hydrolysates for Nile tilapia juveniles. Aquac. Res., 51(4), 1681-1688. DOI: 10.1111/are.14514

Andrews, J. W. and Page, J. W. (1974). Growth Factors in the Fish Meal Component of Catfish Diets. The Journal of Nutrition, 104(8), 1091-1096. DOI: 10.1093/jn/104.8.1091

Angell A.R., Pirozzi I., de Nys R., Paul N.A. (2012). Feeding preferences and the nutritional value of tropical algae for the abalone Haliotis asinina. PLoS ONE. 7(6), e38857. DOI: 10.1371/journal.pone.0038857

Barry, K. J., McClure, R. L. and Trushenski, J. T. (2017). Sea clam-derived feeding stimulants enhance acceptability and intake of reduced fish meal, soy-based sunshine bass feeds. N Am J Aquac., 79(1), 115-122. DOI: $10.1080 / 15222055.2016 .1243600$

Bjørnstad, J., Opstvedt, J. and Lunde, G. (1974). Unidentified growth factors in fish meal: Experiments with organic arsenic compounds in broiler diets. Br. Poult. Sci., 15(5), 481-487. DOI: $\underline{10.1080 / 00071667408416136}$

Braaten, B.R. (1979). Bioenergetics - a review on methodology. Finfish Nutrition and Fishfeed Technology, Ed. Halver and Tiews, Berlin. Vol II. 461-504.

Brugère, C., Aguilar-Manjarrez, J., Beveridge, M. C. M. and Soto, D. (2019). The ecosystem approach to aquaculture 10 years on - a critical review and consideration of its future role in blue growth. Rev Aquac., 11, 493-514. DOI: $10.1111 / \mathrm{raq} .12242$

Bureau, D.P., Kaushik, S.J. and Cho, C.Y. (2002). Bioenergetics. In: Fish Nutrition 3rd ed. ed by J.E. Halver and R.W. Hardy. Academic Press San Diego. USA. pp: 1-59.

Carlberg, H., Cheng, K., Lundh, T. and Brännäs, E. (2015). Using self-selection to evaluate the acceptance of a new diet formulation by farmed fish. Appl. Anim. Behav. Sci., 171, 226-232. DOI: 10.1016/j.applanim.2015.08.016

Carnevali, O., Maradonna, F. and Gioacchini, G. (2017). Integrated control of fish metabolism, wellbeing and reproduction: The role of probiotic. Aquaculture 472, 144-155. DOI: 10.1016/j.aquaculture.2016.03.037

Carr, W. E. S., Netherton, III., J. C., Gleeson, R. A. and Derby, C. D. (1996). Stimulants of feeding behavior in fish: Analyses of tissues of diverse marine organisms. The Biological Bulletin, 190(2), 149-160. DOI: $10.2307 / 1542535$

Cathedralbaits.com Link

Cerezuela, R., Meseguer, J. and Angeles E. (2011). Current knowledge in synbiotic use for fish aquaculture. A Review. J. Aquac. Res. Dev., s1, 1-7. DOI: 10.4172/2155-9546.s1-008 
Chakraborty, S.B. and Hancz, Cs. (2011). Application of phytochemicals as immunostimulant, antipathogenic and antistress agents in finfish culture. Rev Aquac., 3(3), 103-119. DOI: 10.1111/j.1753$\underline{5131.2011 .01048 . x}$

Chakraborty, S.B., Horn, P. and Hancz, C. (2014). Application of phytochemicals as growth-promoters and endocrine modulators in fish culture. Rev Aquac., 6(1) 1-19. DOI: $10.1111 / \mathrm{raq} .12021$

Chatzifotis, S., Arias, M.V., Papadakis, I.E. and Divanach, P. (2009). Evaluation of feed stimulants in diets for sea bream (Sparus aurata). Isr J Aquac., 61(4), 315-321.

Chen, Q., Zhao, H., Huang, Y., Cao, J., Wang, G., Sun, Y. and Li, Y. (2016). Effects of dietary arginine levels on growth performance, body composition, serum biochemical indices and resistance ability against ammonia-nitrogen stress in juvenile yellow catfish (Pelteobagrus fulvidraco). Anim Nutr., 2(3), 204-210. DOI: 10.1016/j.aninu.2016.07.001

Clarke, A. and Johnson, N.M. (1999). Scaling of metabolic rate with body mass and temperature in teleost fish. J. Anim. Ecol. 68(5), 893-905. DOI: 10.1046/j.1365-2656.1999.00337.x

Clarke, W. C., Virtanen, E., Blackburn, J. and Higgs, D. A. (1994). Effects of a dietary betaine/amino acid additive on growth and seawater adaptation in yearling chinook salmon. Aquaculture, 121(1-3), 137-145. DOI: 10.1016/0044-8486(94)90015-9

Conde-Sieira, M. and Soengas, J.L. (2017). Nutrient sensing systems in fish: impact on food intake regulation and energy homeostasis. Front. Neurosci., 10, Article 603. 1-21. DOI: $\underline{10.3389 / f n i n s .2016 .00603}$

Craig, S. (2009). Understanding fish nutrition, feeds and feeding. Virginia Cooperative Extension, Publication 420-256. Link

Delgado, M.J., Cerdá-Reverter, J.M. and Soengas, J.L. (2017). Hypothalamic integration of metabolic, endocrine, and circadian signals in fish: involvement in the control of food intake. Front. Neurosci., 11, Article 354. 1-29. DOI: 10.3389/fnins.2017.00354

Derby, C. D. (2000). Learning from spiny lobsters about chemosensory coding of mixtures. Physiol. Behav., 69(1-2), 203-209. DOI: 10.1016/s0031-9384(00)00202-X

Derby, C. D. and Sorensen, P. W. (2008). Neural Processing, Perception, and Behavioral Responses to Natural Chemical Stimuli by Fish and Crustaceans. J. Chem. Ecol., 34(7), 898-914. DOI: $\underline{10.1007 / s 10886-008-9489-0}$

Derby, C. D., Steullet, P., Horner, A. J. and Cate, H. S. (2001). The sensory basis to feeding behavior in the Caribbean spiny lobster Panulirus argus. Mar. Freshw. Res 52(8), 1339-1350. DOI: $\underline{10.1071 / \mathrm{mf01099}}$

Dietz, C., Stiller, K.T., Griese, M., Schilz and C., Susenbeth, A. (2013). Influence of salinity on energy metabolism in juvenile turbot, Psetta maxima (L.). Aquac Nutr., 19(1), 135-150. DOI: $\underline{10.1111 / a n u .12034}$

Dworjanyn, S. A., Pirozzi, I. and Liu, W. (2007). The effect of the addition of algae feeding stimulants to artificial diets for the sea urchin Tripneustes gratilla. Aquaculture, 273(4), 624-633. DOI: $\underline{10.1016 / j . a q u a c u l t u r e .2007 .08 .023}$

Encarnação, P. (2016). Functional feed additives in aquaculture feeds. pp. 217-237. In Aquafeed Formulation. Biomin Singapore Pte Ltd, Singapore

EFSA (2018). Opinion on the safety and efficacy of L-arginine produced by fermentation with Escherichia coli NITE BP-02186 for all animal species. EFSA Journal 16(5):5276, 1-21. DOI: $\underline{10.2903 / \text { j.efsa. } 2018.5276}$

FAO (2018). The State of World Fisheries and Aquaculture. Link

Ganguly, S., Dora, K., Sarkar, S., and Chowdhury, S. (2013). Supplementation of prebiotics in fish feed: a review. Rev Fish Biol Fisheries, 23(2), 195-199. DOI: 10.1007/s11160-012-9291-5 
Glencross, B.D., Booth, M. and Allan G.L. (2007). A feed is only as good as its ingredients - a review of ingredient evaluation strategies for aquaculture feeds. Aquac Nutr., 13(1). 17-34. DOI: 10.1111/j.1365-2095.2007.00450.x

Gonçalves, R. and Santos, G. (2017). Feed Additives for Profitable, Sustainable Aquaculture. BIOMIN Holding GmbH, Getzersdorf, Austria. pp 20. Link

Grisdale-Helland, B., Takle, H. and Helland, S. J. (2013). Aerobic exercise increases the utilization efficiency of energy and protein for growth in Atlantic salmon post-smolts. Aquaculture, 406-407, 4351. DOI: 10.1016/j.aquaculture.2013.05.002

Hara, T. J. (1994). The diversity of chemical stimulation in fish olfaction and gustation. Rev Fish Biol Fisheries, 4(1), 1-35. DOI: $10.1007 /$ bf00043259

Hara, T.J. (1992). (ed.) Fish chemoreception. Springer, Dordrecht. DOI: 10.1007/978-94-011-2332-7

Hardy, R.W. (2000). New developments in aquatic feed ingredients, and potential of enzyme supplements. In: Cruz-Suarez et al (eds.) Avances en Nutrición Acuicola V. Memorias del V Simposium Internacional de Nutrición Acuicola19-22 Novembre 2000. Mérida Yucatán Mexico. 216-226.

Heinitz, M. C., Lemme, A. and Schulz, C. (2015). Measurement of digestibility in agastric fish based on stripping method - apparent nutrient, energy and amino acid digestibilities of common feed ingredients for carp diets (Cyprinus carpio). Aquac Nutr., 22(5), 1065-1078. DOI: 10.1111/anu.12324

Helland, S.J., Grisdale-Helland, B. and Nerland, S. (1996). A simple method for the measurement of daily feed intake of groups of fish in tanks. Aquaculture, 139(1-2), 157-163. D0I: 10.1016/00448486(95)01145-5

Hien, T. T. T., Phu, T. M., Tu, T. L. C., Tien, N. V., Duc, P. M. and Bengtson, D. A. (2016). Effects of replacing fish meal with soya protein concentrate on growth, feed efficiency and digestibility in diets for snakehead, Channa striata. Aquac. Res., 48(6), 3174-3181. DOI: 10.1111/are.13147

Hirt-Chabbert, J. A., Skalli, A., Young, O. A. and Gisbert, E. (2011). Effects of feeding stimulants on the feed consumption, growth and survival at glass eel and elver stages in the European eel (Anguilla anguilla). Aquac Nutr., 18(2), 152-166. DOI: 10.1111/j.1365-2095.2011.00883.X

Holdt, S.L. and Kraan, S. (2011). Bioactive Compounds in Seaweed: Functional Food Applications and Legislation. J Appl Phycol, 23(3), 543-597. DOI: 10.1007/s10811-010-9632-5

Hossain, M. S., Koshio, S. and Kestemont, P. (2019). Recent advances of nucleotide nutrition research in aquaculture: a review. Rev Aquac., 12(2), 1028-1053. DOI: $10.1111 / \mathrm{raq} .12370$

Houlihan, D., Bouiard, T. and Jobling, M., eds. Food Intake in Fish. (2001). Iowa State University Press. Blackwell Science Ltd. pp. 418.

Jobling, M. (1998). Feeding and nutrition in intensive fish farming. In Biology of farmed fish. Black and Pickering (eds.) Sheffield Academic Press. 1998. ISBN 1-85075-877-8

Johnston, I.A. and Dunn, J. (1987) Temperature acclimation and metabolism in ectotherms with particular reference to teleost fish. Symp Soc Exp Biol., 41, 67-93.

Jones, K. A. (1992). Food search behaviour in fish and the use of chemical lures in commercial and sports fishing. Fish Chemoreception, 288-320. DOI: 10.1007/978-94-011-2332-7 14

Kader, M. A., Koshio, S., Ishikawa, M., Yokoyama, S. and Bulbul, M. (2010). Supplemental effects of some crude ingredients in improving nutritive values of low fishmeal diets for red sea bream, Pagrus major. Aquaculture, 308(3-4), 136-144. DOI: 10.1016/j.aquaculture.2010.07.037

Kasumyan, A. O. and Tinkova, T. V. (2013). Taste attractiveness of different hydrobionts for roach Rutilus rutilus, bitterling Rhodeus sericeus amarus, and rainbow trout Oncorhynchus mykiss. J. Ichthyol. 53(7), 499-508. DOI: $\underline{10.1134 / s 0032945213040024}$

Kaushik, S. J. (1986). Environmental effects on feed utilization. Fish Physiol Biochem., 2(1-4), 131-140. DOI: $\underline{10.1007 / b f 02264081}$ 
Kaushik, S. J. and de Oliva Teles, A. (1985). Effect of digestible energy on nitrogen and energy balance in rainbow trout. Aquaculture, 50(1-2), 89-101. DOI: 10.1016/0044-8486(85)90155-3

Kazerani, H.R. and Shahsavani, D. (2011). The effect of supplementation of feed with exogenous enzymes on the growth of common carp. Iran. J. Vet. Res., 12(2), 127-132.

Kim, H. S. and Cho, S.H. (2019). Dietary inclusion effect of feed ingredients showing high feeding attractiveness to rockfish (Sebastes schlegeli Hilgendorf 1880) on the growth performance, feed utilization, condition factor and whole body composition of fish (II). Comp. Biochem. Physiol. Part A: Molecular and Integrative Physiology. 231, 66-76. DOI: 10.1016/j.cbpa.2019.01.011

Kronveit, R.I., Bendiksen, E.A. and Aunsmo, A. (2014). Field monitoring of feed digestibility in Atlantic salmin farming using crude fiber as an inert marker. Aquaculture, 426-427, 249-255. DOI: $\underline{10.1016 / j . a q u a c u l t u r e .2014 .02 .015}$

Li, P. and Gatlin, D.M. (2006). Nucleotide nutrition in fish: Current knowledge and future applications. Aquaculture, 251(2-4):141-152. DOI: 10.1016/j.aquaculture.2005.01.009

Lim, L.-S., Chor, W.-K., Tuzan, A.D., Shapawi, R. and Kawamura, G. (2016a). Betaine is a feed enhancer for juvenile grouper (Epinephelus fuscoguttatus) as determined behaviourally. J. Appl. Anim. Res., 44(1), 415-418, DOI: 10.1080/09712119.2015.1091329

Lim, L.-S., Lai, S.-K. J., Yong, A. S.-K., Shapawi, R. and Kawamura, G. (2016b). Evaluation on the potential of betaine, taurine, nucleotide and nucleoside as feeding stimulant for juvenile marble goby marmoratus through behavioural assays. Int Aquat Res., 8(2), 161-167. DOI: 10.1007/s40071-016$\underline{0131-4}$

Lindstedt, K.J. (1971). Chemical control of feeding behavior. Comp. Biochem. Physiol., Vol. 39A: 553581.

Liu, L.W., Liang, X.-F., Li, J., Yuan, X.C., Fang, J.G. (2017). Effects of supplemental phytic acid on the apparent digestibility and utilization of dietary amino acids and minerals in juvenile grass carp (Ctenopharyngodon idellus). Aquac Nutr., 24(2), 850-857. DOI: 10.1111/anu.12614

Lovell R. T. (1989). Nutrition and feeding of fish. Van Nostrand Reinhold; New York. pp. 260.

Lovell, R.T. (1991). Nutrition of aquaculture species. J. Anim. Sci., 69, 4193-4200.

Mackie, A.M. and Mitchell, A. I. (1983). Studies on the chemical nature of feeding stimulants for the juvenile European eel, Anguilla anguilla (L.). J. Fish Biol., 22(4), 425-430. DOI: 10.1111/j.10958649.1983.tb04764.x

Mackie, A.M. and Mitchell, A.I. (1982). Further studies on the chemical control of feeding behaviour in the Dover Sole, Solea solea. Comparative Biochemistry and Physiology Part A: Physiology, 73(1), 89-93. DOI: 10.1016/0300-9629(82)90097-4

Magalhães, R., Sánchez-López, A., Leal, R.S., Oliva-Teles, A. and Peres, H. (2017). Black soldier fly (Hermetia illucens) pre-pupae meal as a fish meal replacement in diets for European seabass (Dicentrarchus labrax). Aquaculture 476, 79-85. DOI: 10.1016/j.aquaculture.2017.04.021

Michel, W. C. (2006). Chemoreception. in The Physiology of Fishes. ed. by David H. Evans, James B. Claiborne, Suzanne Currie, 3rd ed., CRC Press Taylor \& Francis, pp. 471 - 497.

Miyasaki T. and Harada, K. (2002). Feeding attractants and stimulants for aquatic animals. Fish Sci., 68(sup2), 1406-1409. DOI: 10.2331/fishsci.68.sup2_1406

Morais S. (2017). The physiology of taste in fish: potential implications for feeding stimulation and gut chemical sensing. Rev. Fish. Sci. Aquac., 25(2), 133-149. DOI: 10.1080/23308249.2016.1249279

NOAA/USDA (2011). NOAA Technical Memorandum NMFS F/SPO-124. The Future of Aquafeeds. Link

Nunes, A. J. P., Sá, M. V. C., Browdy, C. L. and Vazquez-Anon, M. (2014). Practical supplementation of shrimp and fish feeds with crystalline amino acids. Aquaculture, 431, 20-27. DOI: $\underline{10.1016 / j . a q u a c u l t u r e .2014 .04 .003}$ 
Oliveira, A. M. B. de M. S. de and Cyrino, J. E. P. (2004). Attractants in plant protein-based diets for the carnivorous largemouth bass Micropterus salmoides. Sci Agric., 61(3), 326-331. DOI: $\underline{10.1590 / s 0103-90162004000300015}$

Olsén, K. H. and Lundh, T. (2016). Feeding stimulants in an omnivorous species, crucian carp Carassius carassius (Linnaeus 1758). Aquac. Rep., 4, 66-73. DOI: 10.1016/j.aqrep.2016.06.005

Opstvedt, J. and Gjefsen, T. (1975). Unidentified growth factors in fish meal: effects of low levels of fish meal in diets for breeder broiler hens. Poult. Sci., 54(6), 2054-2065. DOI: 10.3382/ps.0542054

Papatryphon, E. and Soares, J. H. (2001). Optimizing the levels of feeding stimulants for use in high-fish meal and plant feedstuff-based diets for striped bass, Morone saxatilis. Aquaculture, 202(3-4), 279-288. DOI: 10.1016/s0044-8486(01)00778-5

Park, Y., Alayafi, A., Bennett, J. L., Malloy, D., Smith, P. M., Ross, N. W., Gagnon, G. A. and Donaldson, A. A. (2019). Modeling the fate of dietary 17B-estradiol and its metabolites in an American eel (Anguilla rostrata) recirculating aquaculture system. Aquac Eng., 86, 101995, 1-8. DOI: 10.1016/j.aquaeng.2019.101995

Parra, L., García, L., Sendra, S. and Lloret, J. (2018). The use of sensors for monitoring the feeding process and adjusting the feed supply velocity in fish farms. J. Sensors, 2018, 1-14. DOI: $10.1155 / 2018 / 1060987$

Pucher, J., Ngoc, T.N., ThiHanYen, T., Mayrhofer, R., El-Matbouli, M., Focken, U. (2014) Earthworm meals fishmeal replacement in plant based feeds for common carp in semi-intensive aquaculture in rural Northern Vietnam. Turkish J. Fish. Aquat. Sci., 14, 557-565.

Reig, L., Ginovart, M. and Flos, R. (2003). Modification of the feeding behaviour of sole (Solea solea) through the addition of a commercial flavour as an alternative to betaine. Aquat. Living Resour., 16(4), 370-379. DOI: 10.1016/s0990-7440(03)00062-7

Ringø, E., Olsen, R.E., Vecino, J.L.G., Wadsworth, S. and Song, S.K. (2012). Use of immunostimulants and nucleotides in aquaculture: a review. J Marine Sci Res Development 2(1), 1000104, 1-22. DOI: $\underline{10.4172 / 2155-9910.1000104}$

Rønnestadt, I., Gomes A.S., Murashita K., Angotzi R., Jönsson E. and Volkoff H. (2017). Appetite-controlling endocrine systems in teleosts. Front. Endocrinol., 8, article73, 1-24. DOI: 10.3389/fendo.2017.00073

Sanchez, D. R., Fox, J. M., Lawrence, A. L., Castille, F. L. and Dunsford, B. (2007). A Methodology for Evaluation of Dietary Feeding Stimulants for the Pacific White Shrimp, Litopenaeus vannamei. J World Aquac Soc., 36(1), 14-23. DOI: 10.1111/j.1749-7345.2005.tb00126.X

Sayer, M.D.J. (1998). Manipulating fish behavior. in Biology of farmed fish. Black and Pickering (eds.) Sheffield Academic Press. 1998. ISBN 1-85075-877-8

Senzui, A., Masumoto, T. and Fukada, H. (2019). Neuropeptide Y expression in response to sensory organ-detected fish meal soluble components and orally fed fish meal-based diet in yellowtail Seriola quinqueradiata. Aquaculture, 514, 734512. DOI: 10.1016/j.aquaculture.2019.734512

Slaski, R. J. and Franklin, P. T. (2011). A review of the status of the use and potential to use micro and macroalgae as commercially viable raw material sources for aquaculture diets. Report commissioned by SARF, pp. 94. Link

Smith, L.S. (1980). Digestion in teleost fish. Aquaculture development and coordination programme. Fish feed technology. FAO Link

Stadtlander, T., Khalil, W.K., Levavi-Sivan, B., Kerem, Z., Dweik, H., Qutob, M., Abu-Lafi, S., Focken, U. and Becker, Z. (2013). Effects of saponon fractions from fenugreek and the soap bark tree in the diet on performance of Nile Tilapia Oreochromis niloticus. Planta Med., 79(13), SL-64. DOI: 10.1055/s$\underline{0033-1351889}$ 
Tacon, A.G.J., (1987). The nutrition and feeding of farmed fish and shrimp - A training manual. FAO, Brasilia, Brazil. Link

Takakuwa, F., Masumoto, T, Toshiro and Haruhisa, F. (2019). Identification of feeding stimulants for greater amberjack Seriola dumerili in muscle tissue of jack mackerel Trachurus japonicus. Fish Sci., 85(2), 387-395. DOI: 10.1007/s12562-018-01285-w

Takaoka, O., Takii, K., Nakamura, M., Kumai, H. and Takeda, M. (1995). Identification of feeding stimulants for tiger puffer. Fish Sci., 61(5), 833-836. DOI: 10.2331/fishsci.61.833

Takeda, M., Takii, K. and Matsui, K. (1984). Identification of feeding stimulants for juvenile eel. Nippon Suisan Gakkaishi, 50(4), 645-651. DOI: 10.2331/suisan.50.645

Teuling, E., Wierenga, P. A., Schrama, J. W. and Gruppen, H. (2017). Comparison of protein extracts from various unicellular green sources. J. Agric. Food Chem., 65(36), 7989-8002. DOI: $\underline{10.1021 / a c s . j a f c .7 b 01788}$

Toften, H. and Jobling, M. (1997). Feed intake and growth of Atlantic salmon, Salmo salar L., fed diets supplemented with oxytetracycline and squid extract. Aquac Nutr. 3(3), 145-151. DOI: $\underline{10.1046 / j .1365-2095.1997 .00081 . x}$

Toften, H., Arnesen, A. M. and Jobling, M. (2003). Feed intake, growth and ionoregulation in Atlantic salmon (Salmo salar L.) smolts in relation to dietary addition of a feeding stimulant and time of seawater transfer. Aquaculture, 217(1-4), 647-662. DOI: 10.1016/s0044-8486(02)00404-0

Tytler, P. and Calow, P. (1985). In "Fish energetic: New Perspectives". Croom Helm, London.

Vahl, O. (1979). An hypothesis on the control of food intake in fish. Aquaculture, 17(3), 221-229. DOI: $\underline{10.1016 / 0044-8486(79) 90125-X}$

Valentičič, T. (2005). Taste and olfactory stimuli and behavior in fishes, pp. 65-85, in G. von der Emde, J. Mogdans, and B. G. Kapoor (eds.). Senses of Fish. Narosa, New Delhi.

Volkoff H. (2016). The neuroendocrine regulation of food intake in fish: A review of current knowledge. Front. Neurosci., 10, article540.1-31. DOI: 10.3389/fnins.2016.00540

Webster, C.D. and Lim, C. (eds.) (2002). Nutrition and fish health. Food Products Press. New York-London-Oxford pp. 365.

Wei, Y., Liang, M., Mu, Y., Zheng, K. and Xu, H. (2015). The effect of ultrafiltered fish protein hydrolysate level on growth performance, protein digestibility and mRNA expression of PepT1 in juvenile turbot (Scophthalmus maximusL.). Aquac Nutr., 22(5), 1006-1017. DOI: 10.1111/anu.12319

Xia, S., Zhao, W., Li, M., Zhang, D., Nan, L., Qian, H., L., Guo, C., Yang and Xuyun, G. (2019). Influence of 5' inosine monophosphate and $5^{\prime}$-guanosine monophosphate on growth, feed digestibility and activity of digestive enzymes in turbot Scophthalmus maximus. Aquac Nutr., 26(1), 165-173. DOI: $\underline{10.1111 / a n u .12978}$

Xue, M., Xie, S. and Cui, Y. (2004). Effect of a feeding stimulant on feeding adaptation of gibel carp Carassius auratus gibelio (Bloch), fed diets with replacement of fish meal by meat and bone meal. Aquac. Res., 35(5), 473-482. DOI: 10.1111/j.1365-2109.2004.01041.x

Yeşilayer, N. and Kaymak, I.E. (2020). Effect of partial replacement of dietary fish meal by soybean meal with betaine attractant supplementation on growth performance and fatty acid profiles of juvenile rainbow trout (Oncorhynchus mykiss). Aquaculture Research. 51(4), 1533-1541. DOI: 10.1111/are.14501

Zou, Q., Huang, Y., Cao, J., Zhao, H., Wang, G., Li, Y. and Pan, Q. (2017). Effects of four feeding stimulants in high plant-based diets on feed intake, growth performance, serum biochemical parameters, digestive enzyme activities and appetite-related genes expression of juvenile GIFT tilapia (Oreochromis sp.). Aquaculture Nutrition, 23(5), 1076-1085. DOI: 10.1111/anu.12475 